\title{
Management of Complex Mandible Fractures
}

\author{
Tom Shokri, MD ${ }^{1}$ Emily Misch, MD ${ }^{2}$ Yadranko Ducic, MD, FRCS(C), FACS 3 Mofiyinfolu Sokoya, MD ${ }^{2}$
}

\author{
${ }^{1}$ Department of Otolaryngology, Penn State Health Milton S Hershey \\ Medical Center, Hershey, Pennsylvania \\ 2 Department of Otolaryngology, University of Colorado, Denver, \\ Colorado \\ 3 Otolaryngology and Facial Plastic Surgery Associates, Fort Worth, \\ Texas
}

Facial Plast Surg 2019;35:602-606.

\author{
Address for correspondence Tom Shokri, MD, Department of \\ Otolaryngology, Penn State Health Milton S Hershey Medical Center, \\ 500 University Ave, Hershey, PA 17033 \\ (e-mail: tshokri@pennstatehealth.psu.edu).
}

\author{
Abstract \\ Keywords \\ - comminuted \\ mandible fracture \\ - atrophic mandible \\ fractures \\ - mandible continuity \\ defect \\ - mandible fractures
}

Mandible fractures represent a common sequela of craniomaxillofacial trauma encountered by reconstructive surgeons. Management of complex mandibular fractures, and reestablishment of the occlusal relationship, represents a challenging reconstructive endeavor for even the most skilled surgeon. In this article, the authors review the treatment options for particularly complex presentations of this injury pattern.
Complex fractures of the mandible, which play an important role in both structural support and masticatory function, pose a significant challenge to the reconstructive surgeon. Advances in the techniques of rigid internal fixation in atrophic, comminuted, and defect fractures have allowed for improved surgical outcomes. The application of basic reconstructive principles and implementation of bone grafting have facilitated convalescence of function and shortened patient treatment course in this setting. Herein, we present a contemporary review of evidence-based management modalities in treatment of complex mandibular fractures.

\section{Management of Initially Infected Mandible Fractures}

Although there is a paucity of evidence supporting postoperative administration of antibiotics in mandible fractures, ${ }^{1,2}$ preoperative administration has shown substantial benefit in reducing infection. ${ }^{3-7}$ Patients presenting with open fractures, fractures along the dentate mandible with violation of the periodontal ligament, should receive antibiotic prophylaxis regardless of planned treatment modality. ${ }^{5-7}$ Antibiotic therapy should also be considered in patients with multiple systemic medical comorbidities and smokers, as these patients have shown an increased incidence of infections. ${ }^{6}$
Infected mandibular fractures present in bimodal patient age distribution patterns. ${ }^{8}$ Interpersonal violence is the primary cause of the majority of mandibular fractures in young males. ${ }^{9-11}$ These patients may seek care in a delayed fashion once symptomology, consistent with underlying infection, necessitates evaluation. Similarly, elderly patients with maxillofacial injury may go unnoticed until infection ensues. ${ }^{12}$ In general, some clinicians propose that all patients with mandibular fractures presenting after 48 hours of onset of injury should be treated as infected..$^{13}$ However, the literature supporting this is limited. All patients presenting with fractures of the mandible should be evaluated for purulent drainage from fracture site, fistula formation, or surrounding cellulitic reaction. A decision on antibiotic therapy should be made on a case-by-case basis.

Historically, infected mandibular infections were treated with extraction of involved dentition with subsequent rigid immobilization of the fracture with maxillomandibular fixation (MMF), intraoral splints, external fixation devices, or a combination of these techniques. ${ }^{14}$ Drainage of surrounding abscesses with prolonged antibiotic treatment was initially thought to be of paramount importance in resolution of infectious processes. However, it was later demonstrated that the nidus of infection, devitalized dentition and osseous fragments, necessitated debridement to mitigate further infection and prevent sequestrum formation..$^{14,15}$ Debridement of
Issue Theme Contemporary Management of Facial Trauma and Complications; Guest Editor: Yadranko Ducic, MD, FRCS(C), FACS

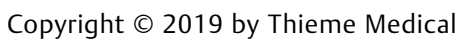
Publishers, Inc., 333 Seventh Avenue, New York, NY 10001, USA. Tel: +1(212) 584-4662. 
infected or devitalized tissue followed by concurrent rigid internal fixation has shown outcomes comparable to noninfected mandibular fractures. ${ }^{16}$ However, debridement of an extensively infected fracture site may result in an osseous defect. In this case, immediate primary bone grafting with autogenous particulate marrow has shown to be effective with decreased overall time to recovery. ${ }^{14-16}$

\section{Management of Teeth in the Fracture Line}

Retained teeth were previously thought to act as a conduit for bacterial migration between the oral cavity and periodontal space and were therefore prophylactically removed. As mentioned previously, frankly infected or devitalized dentition within the fracture line should be extracted, as they may serve as a nidus for infection with resultant sequestrum formation and nonunion. ${ }^{17}$ However, extraction of viable uninfected dentition may cause further trauma to the surrounding bone with destabilization of the fracture. Healthy dentition facilitates proper alignment of premorbid occlusion and should be attempted to be preserved. ${ }^{18}$ Extraction of otherwise healthy dentition may also increase the risk of infection as coagulum formation does not always occur as anticipated, resulting in a localized osteitis. ${ }^{17-19}$ Indications for removal of dentition within the fracture line include clinical or radiologic evidence of periodontal disease, partially erupted third molars with pericoronitis, dentition inhibiting fracture reduction, fragmented dental roots or exposed root apices with loss of gingival margin, and recurring abscess formation despite prolonged antibiotic treatment. ${ }^{17,18}$

Despite these widely accepted indications, controversy persists surrounding extraction of third molars in mandibular angle fractures. ${ }^{17-24}$ Recent evidence supports retention of third molars in the absence of infection or other previously mentioned indications above, as extraction may destabilize the fracture line and prevent interfragmentary stabilization required for osteosynthesis. ${ }^{17,20}$

\section{Management of the Atrophic Edentulous Mandible}

Atrophic mandibular fractures are classified as those with less than $15 \mathrm{~mm}$ of bone height at the site of fracture. ${ }^{25}$ Atrophic mandibles are more susceptible to fracture due to decreased bone stock. The decrease in bone volume also places these patients at higher risk of nonunion due to the tenuous blood supply. Studies have shown significantly higher rates of nonunion if any management modality other than rigid internal fixation is implemented in patients with atrophic mandibles. $^{26,27}$

Controversy also exists surrounding a supraperiosteal or subperiosteal surgical approach to fixation. Mandibular fractures are usually exposed in a subperiosteal plane to allow for adequate reduction and placement of fixation plates directly to underlying bone. ${ }^{25-28}$ However, the bloody supply to the bone is provided via the overlying periosteum. There has therefore been conjecture that a supraperiosteal dissection in atrophic mandibles would better preserve perfusion and promote improved healing with decreased risk of nonunion. ${ }^{29,30}$ The evidence supporting the supraperiosteal approach is, however, limited and this plane of dissection provides suboptimal visualization of the fracture line and introduces an obstacle to the application of fixation devices. This increased difficulty may result in an inadequate reduction or fixation with an associated risk of malunion. ${ }^{25}$

The application of bone grafts at the time of initial intervention is also a topic of active debate. Due to the poor vascularity of the atrophic mandible, reconstructive surgeons have advocated for the addition of bone during initial repair to promote healing capacity. ${ }^{25-27}$ However, the harvest of autogenous graft from the tibia or iliac crest in the debilitated elderly patient, often presenting with multiple comorbidities, may add further morbidity to the repair. Traditionally, closed reduction with or without intermaxillary fixation was the standard of care in this patient population but has since lost favor due to high rates of malunion and nonunion. ${ }^{26,27,29,30}$ The paradigm has thus shifted to open reduction via a subperiosteal extraoral approach with placement of locking reconstruction plates fixated either along the lateral or inferior border. Satisfactory results have been reported with use of reconstructive plates or multiple miniplates placed at various locations. ${ }^{25,31,32}$ Ellis and Price recommend the use of a $2.0-\mathrm{mm}$ locking plate, placed using an extraoral subperiosteal approach with immediate supplemental autogenous bone grafting, citing the advantage of thinner plates with lower likelihood for external palpation, plate exposure, or interference with denture placement. They also report facile adaptability of a thinner plate in comparison to the thicker $2.4 \mathrm{~mm}$ reconstruction plate. ${ }^{25}$ The reconstructive surgeon must be cognizant of potential adverse effects of each technique. Use of large bicortical screws with reconstruction plates may cause further fracture in the severely atrophied mandible, stripping of the periosteum resulting in bony necrosis and malunion, or alveolar nerve injury resulting in lower lip dysesthesia. ${ }^{33,34}$ Despite these disadvantages, placement of a reconstruction plate is the treatment modality recommended by the Arbeitsgemeinschaft für Osteosynthesefragen/Association for the Study of Internal Fixation for the treatment of atrophic mandible fractures.

As mentioned previously, the use of immediate autogenous bone grafts remains controversial. There is currently a paucity of convincing evidence that immediate bone grafting is necessary. Acceptable results have been demonstrated both with ${ }^{25}$ and without ${ }^{35}$ supplementation with bone grafts. Justification for use of bone grafts includes poor vascularity and dense cortical bone with insufficient marrow in the atrophic mandible resulting in poor healing ability. Therefore, the addition of autogenous bone grafts is thought to recruit osteocompetent cells to an otherwise deplete area. $^{25-30}$ Disadvantages include donor site morbidity, such as gait disturbance if the hip or lower leg is used, infection, graft resorption, and nonunion. ${ }^{34,35}$ Currently, there is no consensus for the implementation of bone grafts and treatment decisions should be based on the training and experience of the reconstructive surgeon. When utilized, 
bone grafts (from either the iliac crest, anterior tibia, rib, or calvarial bone) may be placed within a containment system of either titanium or resorbable mesh that is contoured to encompass the delineated mandibular defect. ${ }^{25,36}$ The mesh containment system maintains the shape of the graft while preventing migration during the consolidation phase. ${ }^{36}$ In addition to facilitating osseous healing, utilization of simultaneous bone grafting during the initial repair is thought to increase bone stock, preventing further pathological fractures and facilitating dental prosthetic placement. ${ }^{34,36-39}$ Use of alloplastic reconstructive materials has recently been investigated to mitigate the morbidity associated with bone graft harvesting. These materials include hydroxyapatite, glass ceramics, carbonate, or tricalcium phosphate. ${ }^{40}$ Further alternatives to autogenous grafts include tissueengineered scaffolds with the integration of osteoinductive proteins such as human recombinant bone morphogenic protein 2 . These bioactive materials have shown promising results in preliminary studies. ${ }^{41-44} \mathrm{~A}$ review of the bone tissue engineering is beyond the scope of this article. Readers are directed to the references reviewing biomaterials. ${ }^{44-47}$

\section{Comminuted Fractures and Continuity Defects}

Comminuted mandibular fractures are generally the result of high-impact localized injury. Prior series have reported 5 to $10 \%$ of mandibular fractures resulting in comminution with high rates of malunion or nonunion. ${ }^{48,49}$ Historically, open reduction was not pursued in these fracture types as the risk of vascular compromise of the osseous fragments and resultant sequestration was believed to preclude such intervention. ${ }^{48}$ More recently, open reduction and internal fixation techniques have been implemented in these injury patterns (-Figs. 1-3). Rigid fixation of osseous fragments decreases sequestration while promoting an earlier return to function. ${ }^{48-53}$ The entire comminuted fracture complex is exposed and plated using load-bearing osteosynthesis. Nonviable fragments are debrided and the resulting defects are bone grafted. Stabilization with use of load-sharing plates is contraindicated due to the inability for compression of small

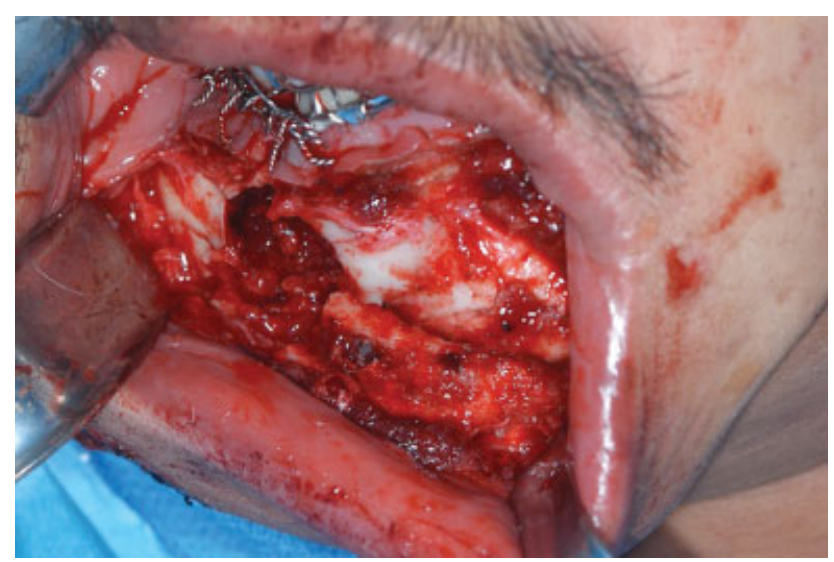

Fig. 1 Intraoperative image displaying continuity defect of mandible following trauma.

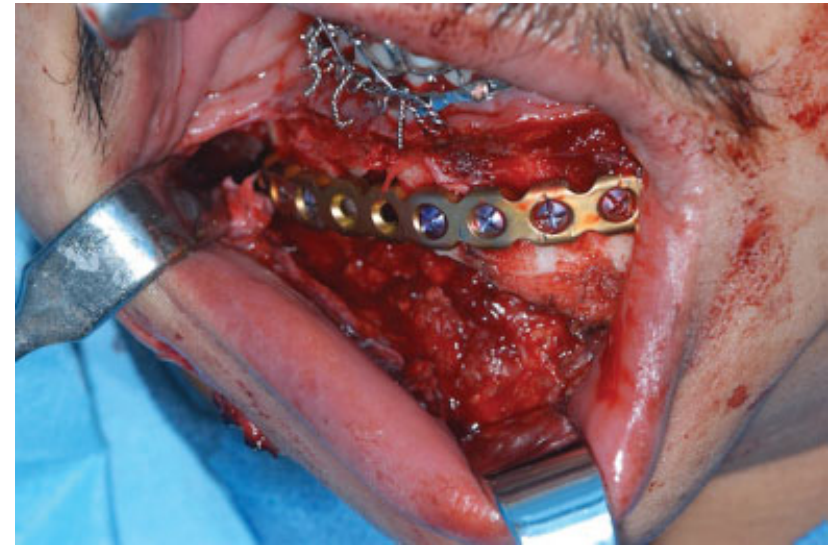

Fig. 2 Placement of large reconstructive plate spanning mandibular defect.

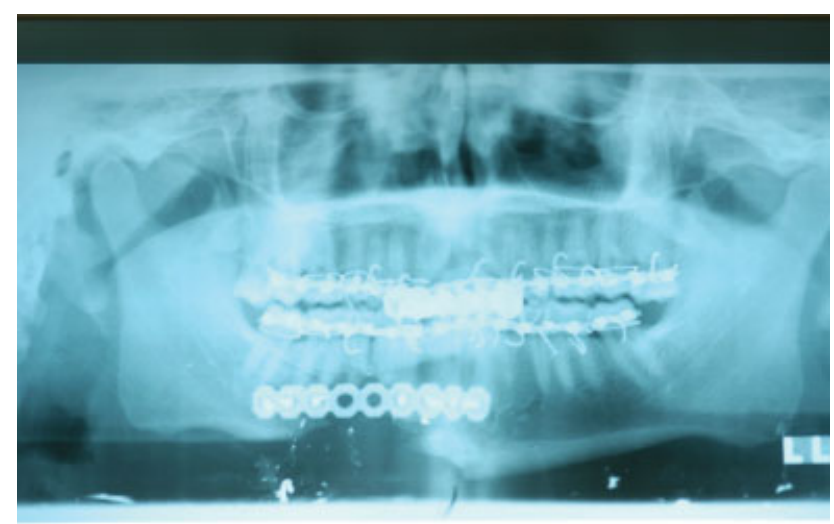

Fig. 3 Radiograph showing maxillomandibular fixation with the placement of reconstructive plate along inferior mandibular border.

fragments. ${ }^{48-50}$ Rigid fixation of projected premorbid occlusion is initially performed with the use of arch bars, wiring, or acrylic splints. An extraoral approach toward fracture exposure is then performed while maintaining the lingual periosteum when possible to stabilize osseous segments and prevent devascularization. Fracture "simplification" is then performed by fastening smaller fragments into larger segments with the use of miniplates or lag screws. This simplified construct is then further stabilized with the use of a locking reconstruction plate with three or more screws on either side of the fracture ends. MMF may then be removed following internal fixation to mitigate ankylosis. ${ }^{44,48-50}$

Comminuted fractures may result in continuity defects following debridement of devitalized osseous fragments. If rigid fixation is implemented in these cases, the lack of micro-movement necessary to stimulate callus formation will prevent neo-osteogenesis. ${ }^{51}$ Placement of autogenous particulate bone with marrow is often necessary in these cases ( - Fig. 4A and B). Vascularized free flap reconstruction represents an alternative method by which continuity defects of the mandible may be reconstructed while allowing for dental implant rehabilitation. ${ }^{54,55}$ The use of biomolecules such as bone morphogenic protein, in combination with allografts, has also shown satisfactory results in 


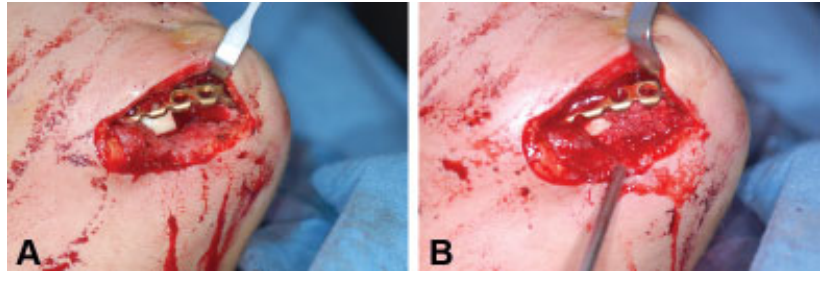

Fig. 4 (A) Mandibular defect with the placement of reconstructive plate across defect. (B) Placement of bone graft with autogenous particulate marrow.

reconstructing large defects. ${ }^{42,44} \mathrm{~A}$ growing understanding of the regenerative capacity of native bone has also led to augmentation with the use of multiple biomolecules that may display summative effects. ${ }^{56,57}$

\section{Gunshot Wounds}

Gunshot wounds (GSWs) to the head and neck region result in severe, destructive injuries that often involve the mandible. A retrospective review looking at outcomes among head and neck GSW patients found that $20 \%$ died within the first 48 hours. Of the remaining cohort, $85 \%$ underwent reconstructive surgery, with patients with mandibular trauma undergoing an average of 1.7 surgical procedures. ${ }^{58}$

The concepts detailed above for comminuted fractures and continuity defects fully apply to GSW-induced mandible fractures, as most of the injuries will be categorized in this manner. However, the mainstay of reconstructing the complex mandible injuries following GSWs is the vascularized free flap. First described in 1989, the fibula free flap remains the mainstay of mandible free flap reconstruction. ${ }^{59}$ Flap options beyond the fibula include the deep circumflex iliac artery, scapula, and osteocutaneous radial forearm free flap. ${ }^{60}$ Fixation of these neomandibles can occur through multiple mini plates or a single reconstructive plate. While some groups have found no difference in outcomes between the two techniques, ${ }^{61}$ others have found that mini plates required removal for infection more frequently. ${ }^{62}$ It is also important to note during surgical planning and patient counseling whether the GSW was selfinflicted, as this puts the patient at higher risk of postoperative complications following free flap reconstruction. ${ }^{63}$

The use of computer-aided design, computer-aided manufacturing, virtual surgical planning, stereolithic models, custom plates, intraoperative navigation, and intraoperative imaging all represent technological advances that are gradually being implemented more frequently in complex mandible reconstructions. ${ }^{60}$ These advances are leading to decreased operative times, decreased costs, and better functional and aesthetic outcomes. ${ }^{60}$

\section{Conclusion}

Complex mandibular injuries represent a unique challenge for the facial trauma surgeon due to the overall extent of injury, risk of infection, dentoalveolar compromise, and possible loss of bone with resultant continuity defects. Rigid fixation of these fractures is of utmost importance in facilitating reconstitution of the mandible, restoration of premorbid occlusion, and convalescence of function. Advances in biomaterials, virtual surgical planning, stereolithic models, and navigation surgery represent future frontiers that may further optimize surgical outcomes in the treatment of these complex injury patterns.

Conflicts of Interest

None.

\section{References}

1 Abubaker AO, Rollert MK. Postoperative antibiotic prophylaxis in mandibular fractures: a preliminary randomized, double-blind, and placebo-controlled clinical study. J Oral Maxillofac Surg 2001; 59(12):1415-1419

2 Miles BA, Potter JK, Ellis E III. The efficacy of postoperative antibiotic regimens in the open treatment of mandibular fractures: a prospective randomized trial. J Oral Maxillofac Surg 2006; 64(04):576-582

3 Zallen RD, Curry JT. A study of antibiotic usage in compound mandibular fractures. J Oral Surg 1975;33(06):431-434

4 Greenberg RN, James RB, Marier RL, Wood WH, Sanders CV, Kent JN. Microbiologic and antibiotic aspects of infections in the oral and maxillofacial region. J Oral Surg 1979;37(12):873-884

5 James RB, Fredrickson C, Kent JN. Prospective study of mandibular fractures. J Oral Surg 1981;39(04):275-281

6 Gutta R, Tracy K, Johnson C, James LE, Krishnan DG, Marciani RD. Outcomes of mandible fracture treatment at an academic tertiary hospital: a 5-year analysis. J Oral Maxillofac Surg 2014;72(03): 550-558

7 Shokri T, Lighthall JG. Antibiotic use in facial plastic surgery. Curr Opin Otolaryngol Head Neck Surg 2018;26(04):242-247

8 Alpert B, Kushner GM, Tiwana PS. Contemporary management of infected mandibular fractures. Craniomaxillofac Trauma Reconstr 2008;1(01):25-29

9 Haug RH, Prather J, Indresano AT. An epidemiologic survey of facial fractures and concomitant injuries. JOral Maxillofac Surg 1990;48(09):926-932

10 Lamphier J, Ziccardi V, Ruvo A, Janel M. Complications of mandibular fractures in an urban teaching center. J Oral Maxillofac Surg 2003;61(07):745-749, discussion 749-750

11 Ogundare BO, Bonnick A, Bayley N. Pattern of mandibular fractures in an urban major trauma center. JOral Maxillofac Surg 2003;61(06):713-718

12 Goldschmidt MJ, Castiglione CL, Assael LA, Litt MD. Craniomaxillofacial trauma in the elderly. JOral Maxillofac Surg 1995;53 (10):1145-1149

13 Maloney PL, Lincoln RE, Coyne CP. A protocol for the management of compound mandibular fractures based on the time from injury to treatment. J Oral Maxillofac Surg 2001;59(08):879-884, discussion 885-886

14 Koury M, Ellis E III. Rigid internal fixation for the treatment of infected mandibular fractures. JOral Maxillofac Surg 1992;50 (05):434-443, discussion 443-444

15 Koury ME, Perrott DH, Kaban LB. The use of rigid internal fixation in mandibular fractures complicated by osteomyelitis. JOral Maxillofac Surg 1994;52(11):1114-1119

16 Benson PD, Marshall MK, Engelstad ME, Kushner GM, Alpert B. The use of immediate bone grafting in reconstruction of clinically infected mandibular fractures: bone grafts in the presence of pus. J Oral Maxillofac Surg 2006;64(01):122-126

17 Gerbino G, Tarello F, Fasolis M, De Gioanni PP. Rigid fixation with teeth in the line of mandibular fractures. Int J Oral Maxillofac Surg 1997;26(03):182-186

18 Spinnato G, Alberto PL. Teeth in the line of mandibular fractures. Atlas Oral Maxillofac Surg Clin North Am 2009;17(01):15-18 
19 Shetty V, Freymiller E. Teeth in the line of fracture: a review. J Oral Maxillofac Surg 1989;47(12):1303-1306

20 Halmos DR, Ellis E III, Dodson TB. Mandibular third molars and angle fractures. JOral Maxillofac Surg 2004;62(09):1076-1081

21 Iizuka T, Lindqvist C, Hallikainen D, Paukku P. Infection after rigid internal fixation of mandibular fractures: a clinical and radiologic study. JOral Maxillofac Surg 1991;49(06):585-593

22 lizuka T, Lindqvist $C$. Rigid internal fixation of fractures in the angular region of the mandible: an analysis of factors contributing to different complications. Plast Reconstr Surg 1993;91(02): 265-271, discussion 272-273

23 Ellis E III. Management of fractures through the angle of the mandible. Oral Maxillofac Surg Clin North Am 2009;21(02):163-174

24 Ellis E III. Outcomes of patients with teeth in the line of mandibular angle fractures treated with stable internal fixation. JOral Maxillofac Surg 2002;60(08):863-865, discussion 866

25 Ellis E III, Price C. Treatment protocol for fractures of the atrophic mandible. J Oral Maxillofac Surg 2008;66(03):421-435

26 Wittwer G, Adeyemo WL, Turhani D, Ploder O. Treatment of atrophic mandibular fractures based on the degree of atrophyexperience with different plating systems: a retrospective study. J Oral Maxillofac Surg 2006;64(02):230-234

27 Madsen MJ, Haug RH, Christensen BS, Aldridge E. Management of atrophic mandible fractures. Oral Maxillofac Surg Clin North Am 2009;21(02):175-183, v

28 Nasser M, Fedorowicz Z, Ebadifar A. Management of the fractured edentulous atrophic mandible. Cochrane Database Syst Rev 2007; (01):CD006087

29 Bradley JC. Age changes in the vascular supply of the mandible. $\mathrm{Br}$ Dent J 1972;132(04):142-144

30 Bradley JC. A radiological investigation into the age changes of the inferior dental artery. Br J Oral Surg 1975;13(01):82-90

31 Melo AR, de Aguiar Soares Carneiro SC, Leal JL, Vasconcelos BC. Fracture of the atrophic mandible: case series and critical review. J Oral Maxillofac Surg 2011;69(05):1430-1435

32 Van Sickels JE, Cunningham LL. Management of atrophic mandible fractures: are bone grafts necessary? J Oral Maxillofac Surg 2010; 68(06):1392-1395

33 Marciani RD. Invasive management of the fractured atrophic edentulous mandible. JOral Maxillofac Surg 2001;59(07):792-795

34 Eyrich GK, Grätz KW, Sailer HF. Surgical treatment of fractures of the edentulous mandible. JOral Maxillofac Surg 1997;55(10): 1081-1087, discussion 1087-1088

35 Luhr HG, Reidick T, Merten HA. Results of treatment of fractures of the atrophic edentulous mandible by compression plating: a retrospective evaluation of 84 consecutive cases. J Oral Maxillofac Surg 1996;54(03):250-254, discussion 254-255

36 Louis P, Holmes J, Fernandes R. Resorbable mesh as a containment system in reconstruction of the atrophic mandible fracture. J Oral Maxillofac Surg 2004;62(06):719-723

37 Woods WR, Hiatt WR, Brooks RL. A technique for simultaneous fracture repair and augmentation of the atrophic edentulous mandible. JOral Surg 1979;37(02):131-135

38 James DR. Atrophy of the mandible: reconstruction following fracture. Br J Oral Surg 1976;14(02):156-162

39 Miloro M, Quinn PD. Prevention of recurrent pathologic fracture of the atrophic mandible using inferior border grafting: report of two cases. J Oral Maxillofac Surg 1994;52(04):414-420

40 Wolff KD, Swaid S, Nolte D, Böckmann RA, Hölzle F, Müller-Mai C. Degradable injectable bone cement in maxillofacial surgery: indications and clinical experience in 27 patients. JCraniomaxillofac Surg 2004;32(02):71-79

41 Bell RB, Gregoire C. Reconstruction of mandibular continuity defects using recombinant human bone morphogenetic protein 2: a note of caution in an atmosphere of exuberance. JOral Maxillofac Surg 2009;67(12):2673-2678
42 Herford AS. rhBMP-2 as an option for reconstructing mandibular continuity defects. J Oral Maxillofac Surg 2009;67(12):2679-2684

43 Shibuya TY, Wadhwa A, Nguyen KH, et al. Linking of bone morphogenetic protein-2 to resorbable fracture plates for enhancing bone healing. Laryngoscope 2005;115(12):2232-2237

44 Herford AS, Boyne PJ. Reconstruction of mandibular continuity defects with bone morphogenetic protein-2 (rhBMP-2). JOral Maxillofac Surg 2008;66(04):616-624

45 Fishero BA, Kohli N, Das A, Christophel JJ, Cui Q. Current concepts of bone tissue engineering for craniofacial bone defect repair. Craniomaxillofac Trauma Reconstr 2015;8(01):23-30

46 Fong KD, Nacamuli RP, Song HM, Warren SM, Lorenz HP, Longaker MT. New strategies for craniofacial repair and replacement: a brief review. JCraniofac Surg 2003;14(03):333-339

47 Tollemar V, Collier ZJ, Mohammed MK, Lee MJ, Ameer GA, Reid RR. Stem cells, growth factors and scaffolds in craniofacial regenerative medicine. Genes Dis 2016;3(01):56-71

48 Ellis E III, Muniz O, Anand K. Treatment considerations for comminuted mandibular fractures. JOral Maxillofac Surg 2003; 61(08):861-870

49 Alpert B, Tiwana PS, Kushner GM. Management of comminuted fractures of the mandible. Oral Maxillofac Surg Clin North Am 2009;21(02):185-192, v

50 Klotch D. Use of rigid internal fixation in the repair of complex and comminuted mandible fractures. Otolaryngol Clin North Am 1987;20(03):495-518

51 Prein J, Kellman RM. Rigid internal fixation of mandibular fractures-basics of AO technique. Otolaryngol Clin North Am 1987;20 (03):441-456

52 Assael LA. Results in rigid internal fixation of highly comminuted fractures of the mandible. JOral Maxillofac Surg 1989;47(08): 119-120

53 Anderson T, Alpert B. Experience with rigid fixation of mandibular fractures and immediate function. J Oral Maxillofac Surg 1992;50 (06):555-560, discussion 560-561

54 Zide MF, Ducic Y. Fibula microvascular free tissue reconstruction of the severely comminuted atrophic mandible fracture-case report. J Craniomaxillofac Surg 2003;31(05):296-298

55 Oliveira ES, Oliveira JI, Silva BB, et al. Use of fibular graft for the treatment of atrophic mandible fracture. Int J Oral Maxillofac Surg 2019;48:266

56 Wang W, Yeung KWK. Bone grafts and biomaterials substitutes for bone defect repair: A review. Bioact Mater 2017;2(04):224-247

57 Wang W, Yeung KW. Bone grafts and bone substitutes for bone defect management. In: Li B, Webster T, eds. Orthopedic Biomaterials. Cham: Springer; 2017:495-545

58 Shackford SR, Kahl JE, Calvo RY, et al. Gunshot wounds and blast injuries to the face are associated with significant morbidity and mortality: results of an 11-year multi-institutional study of 720 patients. J Trauma Acute Care Surg 2014;76(02):347-352

59 Hidalgo DA. Fibula free flap: a new method of mandible reconstruction. Plast Reconstr Surg 1989;84(01):71-79

60 Khatib B, Gelesko S, Amundson M, et al. Updates in management of craniomaxillofacial gunshot wounds and reconstruction of the mandible. Facial Plast Surg Clin North Am 2017;25(04):563-576

61 Robey AB, Spann ML, McAuliff TM, Meza JL, Hollins RR, Johnson PJ. Comparison of miniplates and reconstruction plates in fibular flap reconstruction of the mandible. Plast Reconstr Surg 2008;122 (06):1733-1738

62 Al-Bustani S, Austin GK, Ambrose EC, Miller J, Hackman TG, Halvorson EG. Miniplates versus reconstruction bars for oncologic free fibula flap mandible reconstruction. Ann Plast Surg 2016;77 (03):314-317

63 Sokoya M, Vincent AG, Joshi R, et al. Higher complication rates in self-inflicted gunshot wounds after microvascular free tissue transfer. Laryngoscope 2019;129(04):837-840 